\title{
House Price Dynamics and the Macro-Economy: an Empirical Perspective of UAE
}

\author{
Yahya Hamad Al Zaabi *a, Dr. Genanew Bekele \\ a Dubai Business School (DBS), University of Dubai, Dubai, UAE \\ *Corresponding author.
}

Received: 30 July 2018, accepted: 24 Septembre 2018, published: 31 January 2019

\begin{abstract}
Objective: The paper aims to examine house price drivers in Dubai, addressing the effect of internal and external factors afecting house prices
\end{abstract}

Design/methedology/approach: Using the Hedonic price model, the study examined the implications of house size (space), the availability of bathrooms, bedrooms, waterfronts, and pool and cell phone towers within residential area as auxiliary determinant factors to housing price within developed cities by using the Hedonic Modelling. Also, study highlight the effect of the green strategies that been followed by developer on the housing prices.

Findings: The study is expected to reveal results with significant ramifications for researchers, practitioners and policy makers. From a policy perspective, there is an obvious interest in understanding whether the price of housing is affected by different attributes differently along its distribution.

Research limitations/implications: The data used in this study could be limited, and depends on information to be provided by the Dubai Land Department. There is a room for future research to include more data (such as on other house attributes such as house condition, plot numbers and configuration).

\section{INTRODUCTION}

The rate of urbanization across the globe is a significant feature, which keeps changing based on the associated trends and the need for sustainable effectiveness in planning and implementation of strategies. The changes in the settlement structure indicate a possible change from the migration patterns of more people moving to urban regions. According to the United Commission on Science and Technology for Development (2016), the cities will be densely populated in developed nations as compared to urban centers by 2050. Based on the forecast migration changes will transform the nature of the urban cities and over $60 \%$ of the world's population will be residing in smart cities with modern facilities and technology-based planning and implementations. The level of infrastructure, the capacity of available resources, and the space factor will be essential performance indicators to be examined. Also, the promotion of green strategy in housing development has significant contribution to the implementation of sustainable development principles.

The existence of competent models that will assist in executing strategic plans towards the establishment of sustainable cities is one of the duties performed through succinct research and evaluation of the primary housing prices factors such as space, price or cost, bedrooms, baths, and age. This is a simple research on examining the impact of housing prices by the usual macro determinants (e.g.: Government policies and regulation, Economy, Banking mortges, Developer brand, living standard and regional event), micro determinants (e.g.: Design factors, green technologies, Mobile cell Towers, High Voltage Towers).

Over the year's studies have been carried out to understand the best mechanisms that can be implemented to ensure that the challenges as well as the effectiveness associated with planning, implementing, and sustaining cities resources strategies are controlled. Such a move is essential in operation management as the selection of the best technology https://doi.org/10.30585/icabml-cp.v2i1.209

(c) 2018 the Authors. Production and hosting by Avicenna FZ LLC. on behalf of Dubai Business School, University of Dubai - United Arab Emirates. This is an open access article under the CC BY-NC license. 
measures that will improve the services from public and private entities as most cities are shifting towards megaestablishments. It is clear that with urbanization comes other auxiliary but essential needs such as space, water supply, increased energy demand, and social amenities elements along with the increase demand on the ICT. The need for efficient to manage projected migrations, as well as anticipated population changes, leads to strategic approaches to efficient housing planning and management. Through research, new methods associated with the development of housing services have been established to curb the increasing challenges and demands associated with the shift in settlement patterns. Since the emergence of megacities came with infrastructural complexity, other factors such as greenery environmental, information, and communication technology have emerged. Therefore, the focus is currently on guaranteeing cleaner habitats and with sustainable corporate and sociopolitical environment. However, the housing price determents are one of the critical areas that have not been extensively examined especially in UAE.

\section{JUSTIFICATION OF STUDY}

The process of making cities as comprehensive settlement for people has transformed cities and major settlement areas across the globe. Resources have been used to establish and implement strategies that are meant to enhance the capacity of the towns regarding the increasing migration, social amenities, and infrastructure among other factors. Most of the programs undertaken to build cities such as Amsterdam, San Francisco, Barcelona, and Singapore have focused on infrastructure and other auxiliary services to enhance the environment and structure of the modern cities (United Commission on Science and Technology for Development, 2016). However, such measures have changed the housing prices, which have been escalating since more innovative approaches are included in planning and implementation to enhance the housing services.

Nevertheless, no clear measures have been undertaken to develop preliminary models that link the house prices to other factors such as space, age, baths, bedrooms, and waterfront among others. Therefore, through research and analysis of the housing data has essential correlations with housing price as the dependent variable will assist in making predictions in the sector, which will act as a vital tool for decision making for the public and other stakeholders. Moreover, the implication of ICT infrastructure on the price factor of housing in residential cities can be understood through the evaluation of the regression assumption that is valid for the relationship between the price and the auxiliary factors. This study considered multiple factors that determine the price, which has been encouraged through innovation and technology to make smart cities sustainable and efficient (Ahvenniemi et al., 2016). The approach for the study further offers the best platform to understand the relationship of price and the secondary factors by designing a single relational equation.

\section{CONCEPTUAL FRAMEWORK}

The housing development in cities is one of the essential elements that emanate from the improved planning and implementation of strategic projects for sustainable megacities. Technology has contributed towards infrastructural expertise, which in turn has created a shift in the housing prices across major modern towns. The changes in population structure, tastes, and preference, as well as the level of income, have affected the designs while the increase in population has transformed the use of space (Angelidou, 2015). Therefore, it is clear that the current price of housing in cities cannot be solely linked to economic status, accessibility, or cost of construction but other factors such as age, baths, bedrooms, pool, and waterfront as efficiency needs to influence the pricing rates. The auxiliary elements have a different degree of impact on the price, which needs to be investigated. In this study, the primary objective was to obtain an estimate equation relating housing prices with other factors like Mobile cell towers. Not only this, but also, we want to examine the effect of the green strategy by developer on the housing prices which considered as intervening variable. The expected equation was to depict the effect of each factor as regression coefficients related to the auxiliary factors expressed as a single equation. After analyzing the equation of the housing prices, we want to examine the effect on the economic and the policies. 


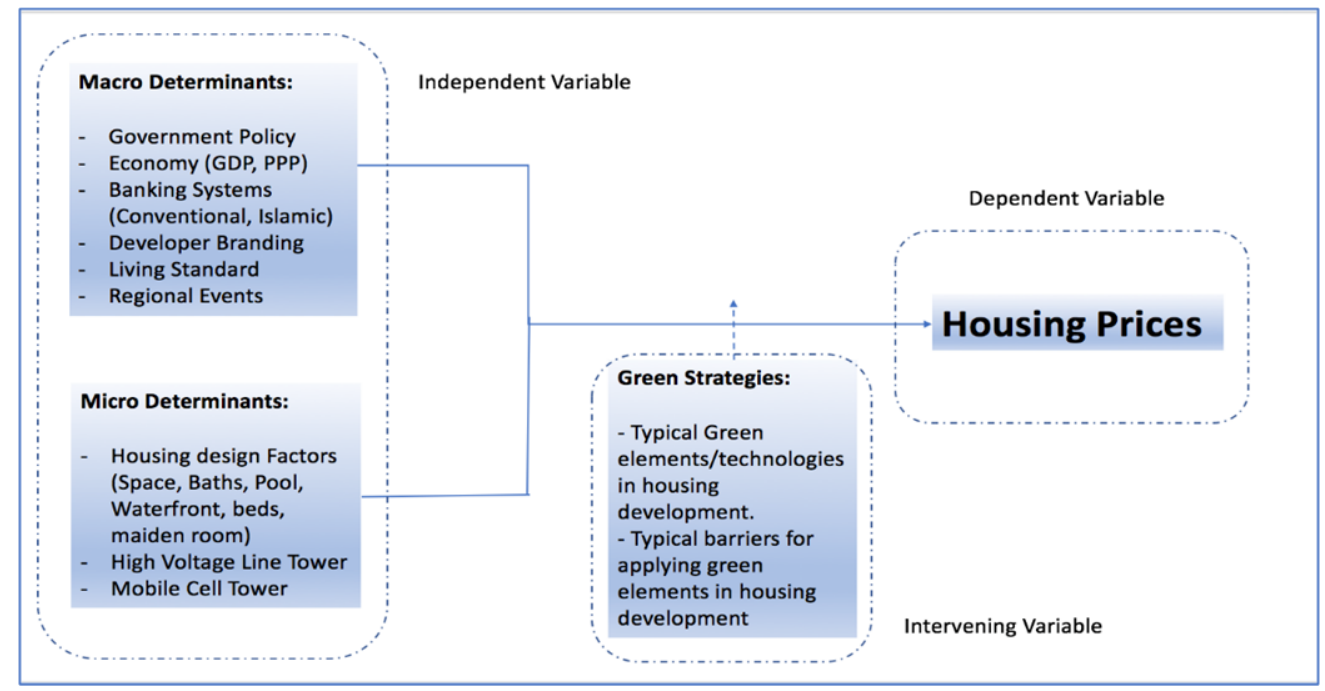

Figure1. Research Conceptual Frame work for Housing prices

\section{RESEARCH DESIGN AND METHODOLOGY}

The process of evaluating the implications of the housing factors about price requires a comprehensive analysis. The study, therefore, involved a qualitative approach to determine the relationship between housing price and space, baths, bedrooms, waterfront and mobile cell tower. The qualitative approach is essential because it provides the analytical approach to the factors under investigation (Travers, 2006; O'Byrne, 2007). The process of investigating a topic of study that involves data provides a clear picture of the scenario since the description of phenomena using numerical values depicts a higher degree of validity. The study includes several variables where correlational relationships are required to provide a precise understanding of the implication of all factors mentioned earlier on the housing prices. The study, therefore, depended on statistical evaluation such as regression, estimated equation, and the measure of over-all goodness to examine the relationship between housing price as the dependent variable and space, baths, bedrooms, waterfronts, pools and cell towers as the auxiliary factors of efficient housing services for smart cities.

Furthermore, the study utilized the Housing Data from Municipalities as the primary source of the research data. The data was significant since it depicted a variety of factors that determine the price of houses in smart cities. The process of evaluation involved the investigation of the regression assumptions that were valid about the topic of study. The analysis was based on the objective of the study as well as the associated hypothesis of the research. The Stata Software aided in analyzing the data based on the selected relationships with price as the primary element of the housing factor. The software is essential because it provides multiple data analysis mechanisms for diverse data such as Estimate Analysis, Regression Analysis, Analysis of Variance, and Advanced Measures of Central Tendencies. Such variables are essential in qualitative research since more measures enhance the validity and reliability of the study.

\section{CONCLUSIONS}

The process of making cities as comprehensive settlement for people has transformed cities and major settlement areas across the globe. Resources have been used to establish and implement strategies that are meant to enhance the capacity of the towns regarding the increasing migration, social amenities, and infrastructure among other factors. Most of the programs undertaken to build cities such as Amsterdam, San Francisco, Barcelona, and Singapore have focused on infrastructure and other auxiliary services to enhance the environment and structure of the modern cities. However, such measures have changed the housing prices, which have been escalating since more innovative approaches are included in planning and implementation to enhance the housing services.

Nevertheless, no clear measures have been undertaken to develop preliminary models that link the house prices to other factors such as space, age, baths, bedrooms, and waterfront among others. Therefore, through research and 
analysis of the housing data has essential correlations with housing price as the dependent variable will assist in making predictions in the sector, which will act as a vital tool for decision making for the public and other stakeholders.

Moreover, the implication of ICT infrastructure on the price factor of housing in residential cities can be understood through the evaluation of the regression assumption that is valid for the relationship between the price and the auxiliary factors. This study considered multiple factors that determine the price, which has been encouraged through innovation and technology to make smart cities sustainable and efficient. The approach for the study further offers the best platform to understand the relationship of price and the secondary factors by designing a single relational equation

\section{References}

Ahvenniemi, H., Huovila, A., Pinto-Seppä, I. and Airaksinen, M., 2016. 'What are the differences between sustainable and smart cities?', Cities, 60pp. 234-245.

Angelidou, M., 2015. 'Smart cities: A conjuncture of four forces', Cities, 47pp. 95-106.

O'Byrne, P., 2007. 'The advantages and disadvantages of mixing methods: An analysis of combining traditional and Autoethnographic approaches', Qualitative Health Research, 17(10), pp. 1381-1391.

Travers, M., 2006. 'Postmodernism and qualitative research', Qualitative Research, 6(2), pp. 267-273.

United Commission on Science and Technology for Development, 2016. Smart cites and infrastructure, UCSTD Intersessional Paper. 